\title{
Expression of TIA-1 and TIA-2 in T cell malignancies and $T$ cell lymphocytosis
}

\author{
E Matutes, E Coelho, M J Aguado, R Morilla, A Crawford, K Owusu-Ankomah, \\ D Catovsky
}

\begin{abstract}
Objective-To investigate the reactivity with TIA-1 and TIA-2, two monoclonal antibodies that recognise, respectively, granular structures in $\mathbf{T}$ lymphocytes and the $T$ cell receptor chain in cells from a variety of $T$ cell disorders.

Methods-Cytoplasmic staining with TIA1 and TIA-2 was carried out by the immunoalkaline phosphatase anti-alkaline phosphatase technique in 67 cases with a $T$ cell disorder: 31 large granular lymphocyte (LGL) leukaemia, nine T-prolymphocytic leukaemia (T-PLL), five Sezary syndrome, four peripheral $T$ cell lymphoma (PTCL), $13 T$ cell lymphocytosis, and five $T$-acute lymphoblastic leukaemia (T-ALL). All had over $75 \%$ abnormal $T$ cells which were $\mathrm{CD} 2+, \mathrm{CD} 3+, \mathrm{CD5}+, \mathrm{CD} 7+$, and negative with $B$ cell markers.
\end{abstract}

Results-TIA-1 was positive in $77 \%$ cases of LGL leukaemia and half of the PTCL and T-ALL, whereas it was negative in all Sezary syndrome and most T-PLL (8/9) and reactive $T$-lymphocytosis $(10 / 13)$. In LGL leukaemia, TIA-1 was positive irrespective of the membrane phenotype, whether CD8 +, CD4 - or CD4 + , CD8-, and was more often positive in cases where cells were $\mathrm{CD} 16+, \mathrm{CD} 56+$, or $\mathrm{CD} 57+$. TIA-2 was positive in $60 \%$ of cases encompassing all diagnostic types of $T$ cell disorder. There was no correlation between TIA-2 expression and that of other $T$ cell markers, activation antigens, and natural killer markers.

Conclusions-The pattern of TIA-1 expression in $T$ cell malignancies may help in the differential diagnosis among LGL leukaemia (high expression), $T$ cell lymphocytosis and other $T$ cell diseases (low expression). As TIA-2 is expressed in over $95 \%$ mature $T$ lymphocytes and thymic cells, its assessment may be useful to demonstrate aberrant phenotypes which can be exploited for detecting minimal residual disease.

(f Clin Pathol 1996;49:154-158)

Keywords: $\mathrm{T}$ cell leukaemias, $\mathrm{T}$ cell lymphocytosis, TCR- $\zeta$ chain, cytotoxic, natural killer.

Malignancies of mature $T$ cells include various entities with distinct clinical and laboratory features. ${ }^{12}$ Most cases are clonal expansions of $\mathrm{CD} 4+, \mathrm{CD} 8$ - lymphocytes except large granular lymphocyte (LGL) leukaemia which has usually a CD8 +, CD4 - phenotype. The expression of other $\mathrm{T}$ cell markers is variable and thus atypical profiles may be found in a proportion of cases. Identification of such phenotypes may be useful for diagnostic and follow up purposes.

New monoclonal antibodies that identify $T$ cell functional molecules have recently become available. TIA-1 is a monoclonal antibody that recognises a $16 \mathrm{kDa}$ cytoplasmic protein localised in the lysosomal granules and Golgi zone in $55 \%$ of CD8 + cytotoxic lymphocytes. ${ }^{3}$ It is also expressed in natural killer (NK) cells, in mitogen activated thymic cells, and in CD4+ and CD4 +, CD8 + lymphocytes. TIA-2 identifies a $32 \mathrm{kDa}$ transmembrane protein with a small extracellular domain and a large intracellular epitope which forms part of the $T$ cell receptor (TCR) complex and is designated TCR- $\zeta$ chain. ${ }^{45}$ This molecule is linked to the CD3 complex in T lymphocytes and to the low affinity Fc $\gamma$ receptor (CD16) in NK cells. ${ }^{5-7}$ The TCR- $\zeta$ chain has a key functional role in NK cells, being involved in antigen recognition, ${ }^{5}$ and it is expressed in $95 \%$ of thymic cells, circulating $\mathrm{T}$ lymphocytes, and NK cells but not on other cells. ${ }^{45}$

The reactivity of TIA-1 and TIA-2 has been investigated in normal haemopoietic tissues, cell lines, and tumour infiltrating lymphocytes, where a decreased expression of TCR $-\zeta$ chain has been linked to impaired immunological surveillance. $^{89}$ Decreased numbers of circulating TCR- $\zeta$ positive T lymphocytes have been documented in a B cell lymphoma and their values shown to parallel disease activity. ${ }^{10}$ In addition, the number of TIA-1 positive lymphocytes in B cell non-Hodgkin's lymphoma correlates with high grade histology, suggesting that they represent a cytolytic anti-tumour response. ${ }^{11}$ There is no information concerning the expression of TIA-1 and TIA-2 in T cell disorders.

We have studied the reactivity of TIA-1 and TIA-2 in T-lymphoproliferative disorders and $T$ cell lymphocytosis to investigate their possible role in differential diagnosis, in defining more precisely the cell nature of these diseases, and disclosing immunophenotypes which can be exploited for the detection of minimal residual disease.

Methods

PATIENTS

Peripheral blood mononuclear cells from 54 patients with a $T$ cell malignancy and 13 with $\mathrm{T}$ cell lymphocytosis have been analysed. These 
Table 1 Antibodies used in this study

\begin{tabular}{|c|c|c|}
\hline Antibody & $C D$ & Source \\
\hline OKT6 & CDla & Orthoclone \\
\hline RFT11 & CD2 & Prof G Janossy (London, UK) \\
\hline UCHT1 & CD3 & Prof $P$ Beverley (London, UK) \\
\hline Leu-3a & CD4 & Beckton-Dickinson \\
\hline UCHT2 & CD5 & Prof P Beverley (London, UK) \\
\hline $3 \mathrm{~A} 1$ & CD7 & Sera-Lab \\
\hline Leu-2A & CD8 & Beckton-Dickinson \\
\hline OKM1 & CD11b & Orthoclone \\
\hline Leu-11 & CD16 & Beckton-Dickinson \\
\hline B4 & CD19 & Coulterclone \\
\hline IL2R & CD25 & Beckton-Dickinson \\
\hline WR17 & CD37 & Dr J Smith (Southampton, UK) \\
\hline OKT10 & CD38 & Orthoclone \\
\hline Leu-19 & CD56 & Beckton-Dickinson \\
\hline Leu-7 & CD57 & Beckton-Dickinson \\
\hline anti-HLA-Dr & & Prof F Garrido (Granada, Spain) \\
\hline $\begin{array}{l}\text { anti-TdT } \\
\text { TIA-1 }\end{array}$ & & Sera-Lab \\
\hline $\begin{array}{l}11 A-1 \\
\text { TIA-2 }\end{array}$ & anti-TCR $\zeta$ & Coulterclone \\
\hline
\end{tabular}

were classified on the basis of clinical, morphological, and immunological features ${ }^{2}$ as follows: LGL leukaemia 31, $\mathrm{T}$ prolymphocytic leukaemia (T-PLL) 9, Sezary syndrome 5 , peripheral $\mathrm{T}$ cell lymphoma (PTCL) 4, and Tacute lymphoblastic leukaemia (T-ALL) 5. All cases had over $75 \%$, usually more than $90 \%$, circulating abnormal lymphocytes. All patients with LGL leukaemia had $>5 \times 10^{9} /$ litre circulating lymphocytes which persisted over one year without an underlying cause. In 14 of these cases, clonality was documented by cytogenetics or DNA analysis of the TCR $\beta, \gamma, \delta$ chain genes.

\section{IMMUNOLOGICAL MARKERS}

Immunophenotyping was performed by indirect immunofluorescence with a panel of monoclonal antibodies against $\mathrm{B}, \mathrm{T}$, and NK cells (table 1) and a fluorescein conjugated (FITC) goat anti-mouse immunoglobulin $\mathrm{F}\left(\mathrm{ab}^{\prime}\right)_{2}$ fragment as second layer. Results were analysed by flow cytometry on a FACscan (Becton-Dickinson) using a lymphocyte gate. To avoid binding of monoclonal antibodies to Fc $\gamma$ receptors, $2 \% \mathrm{AB}$ serum was added to the buffer in all incubations and washes. Controls were prepared by omitting the first layer monoclonal antibodies or replacing with mouse immunoglobulins of the various isotypes, or both. The enzyme terminal deoxynucleotidyl transferase (TdT) was analysed with a rabbit antibody by the immunoalkaline phosphatase antialkaline phosphatase (APAAP) as described. ${ }^{12}$

The reactivity with TIA-1 and TIA-2 was evaluated by the APAAP technique ${ }^{13}$ using a 1

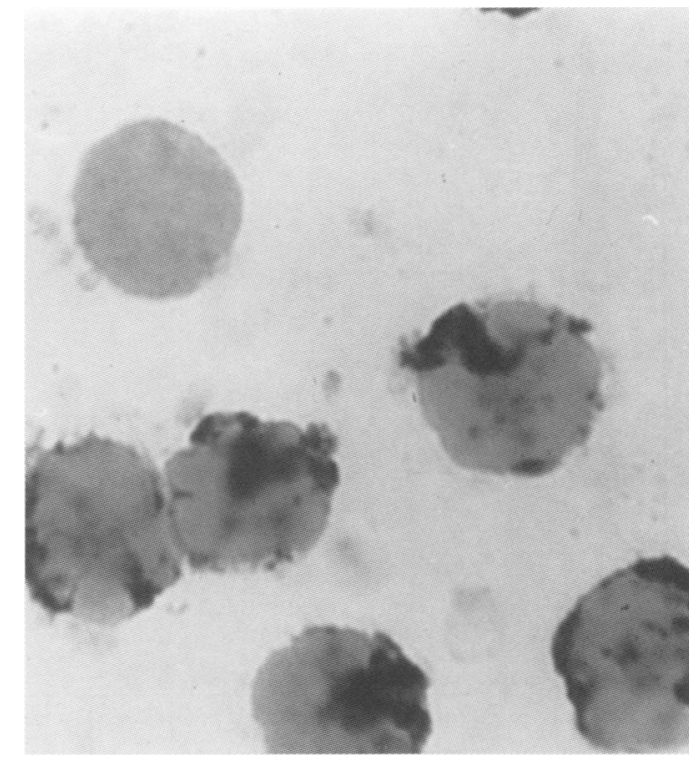

Figure 1 Lymphocytes from a case with LGL leukaemia strongly positive with TIA-1. Note a negative cell (APAAP technique).

in 1000 dilution for TIA- 1 and a 1 in 50 dilution for TIA-2 from a starting concentration as recommended by the manufacturers. Some samples were also investigated by flow cytometry after fixation and permeabilisation of the cell membrane. ${ }^{14} \mathrm{~A}$ case was considered positive with TIA-1 or TIA-2 when more than $30 \%$ cells reacted with either antibody.

The monoclonal antibodies TIA-1 and TIA2 were commercially available from Coulter clone and both are mouse IgG1 ascites fluid.

\section{Results}

\section{IMMUNOLOGICAL MARKERS}

The cells in the cases studied were positive with one or more $\mathrm{T}$ cell markers as follows: CD2 (96\%), CD3 (91\%), CD5 (89\%), and CD7 (78\%), and they were negative with $\mathrm{B}$ cell markers. TdT and/or CD1a were negative in all but the five cases of T-ALL which were $\mathrm{TdT}+$ and two which were CD1a+. Cells from most LGL leukaemias were CD8+, CD4 - whereas a CD4 +, CD8 - phenotype was more frequent in Sezary syndrome and $\mathrm{T}$ cell lymphocytosis, and coexpression of CD4 and CD8 was more frequent in T-PLL (table 2).

Expression of NK associated markers was more common in LGL leukaemia, namely CD11b in 17/27 (63\%) of cases, CD16 in 8/

Table 2 Expression of CD4 and CD8 in $T$ cell diseases (number and proportion of positive cases)

\begin{tabular}{lllllll}
\hline Phenotype & $\begin{array}{l}\text { LGL } \\
\text { leukaemia }\end{array}$ & T-PLL & $S S$ & PTCL & $T-$ ALL & $\begin{array}{l}\text { T cell } \\
\text { lymphocytosis }\end{array}$ \\
\hline CD4+ CD8- & $3 / 31$ & $2 / 9$ & $4 / 5$ & $2 / 4$ & $0 / 3$ & $6 / 9$ \\
& $(10 \%)$ & $(22 \%)$ & $(80 \%)$ & $(50 \%)$ & $(0 \%)$ & $(67 \%)$ \\
CD4- CD8+ & $21 / 31$ & $3 / 9$ & $0 / 5$ & $1 / 4$ & $2 / 3$ & $3 / 9$ \\
CD4+ CD8+ & $(68 \%)$ & $(33 \%)$ & $(0 \%)$ & $(25 \%)$ & $(66 \%)$ & $(33 \%)$ \\
CD4- CD8 - & $1 / 31$ & $4 / 9$ & $1 / 5$ & $0 / 4$ & $0 / 3$ & $0 / 9$ \\
& $(3 \%)$ & $(44 \%)$ & $(20 \%)$ & $(0 \%)$ & $(0 \%)$ & $(0 \%)$ \\
\hline
\end{tabular}




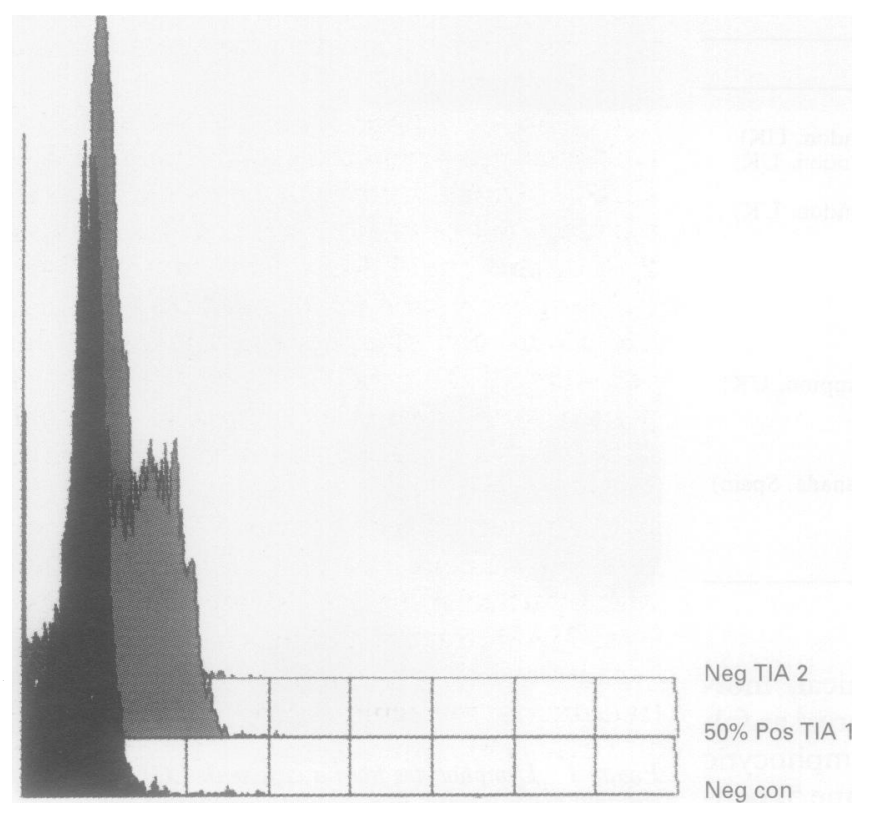

Figure 2 FACS profile showing positive cytoplasmic staining with TIA-1 and negative $T I A-2$ in a case of $L G L$ leukaemia.

Table 3 Expression of TIA-1 and TIA-2 in T cell malignancies and $T$ cell lymphocytosis

\begin{tabular}{|c|c|c|c|}
\hline \multirow[b]{2}{*}{ Disease } & \multirow{2}{*}{$\begin{array}{l}\text { Number } \\
\text { of cases }\end{array}$} & \multicolumn{2}{|c|}{ Number and $\%$ of positive cases } \\
\hline & & $T L A-1$ & $T L A-2$ \\
\hline $\begin{array}{l}\text { LGL leukaemia } \\
\text { T cell lymphocytosis } \\
\text { T-PLL } \\
\text { Sezary syndrome } \\
\text { PTCL } \\
\text { T-ALL }\end{array}$ & $\begin{array}{r}31 \\
13 \\
9 \\
5 \\
4 \\
5\end{array}$ & $\begin{array}{c}24 / 31(77 \%) \\
3 / 31(23 \%) \\
1 / 9(11 \%) \\
0 / 5(0 \%) \\
2 / 4(50 \%) \\
2 / 5(40 \%)\end{array}$ & $\begin{array}{c}17 / 24(71 \%) \\
7 / 13(54 \%) \\
4 / 7(57 \%) \\
2 / 4(50 \%) \\
1 / 4(25 \%) \\
1 / 2(50 \%)\end{array}$ \\
\hline Total & 67 & $32 / 67(48 \%)$ & $32 / 54(60 \%)$ \\
\hline
\end{tabular}

LGL leukaemia $=$ large granular lymphocyte leukaemia; TPLL = T-prolymphocytic leukaemia; PTCL $=$ peripheral T-cell lymphoma; T-ALL = T-acute lymphoblastic leukaemia.

$22(36 \%)$, CD 57 in $13 / 20(65 \%)$, and CD56 in $8 / 22(36 \%)$. These markers were rarely expressed in the other disorders: CD56 in one T-PLL, CD57 + and CD56 + in two Sezary syndrome, and CD11b+, CD16+ in one PTCL. T cell activation markers were variably expressed in all disease types: CD25 in $7 / 29$ (24\%), CD38 in $13 / 25$ (52\%), and class II HLA-Dr in $14 / 37(38 \%)$.

TIA-1 AND TIA-2

The reactivity with TIA-1 and TIA-2 according to disease categories is shown in table 3. TIA1 was positive in $48 \%$ and the proportion of cases and staining intensity was higher in LGL

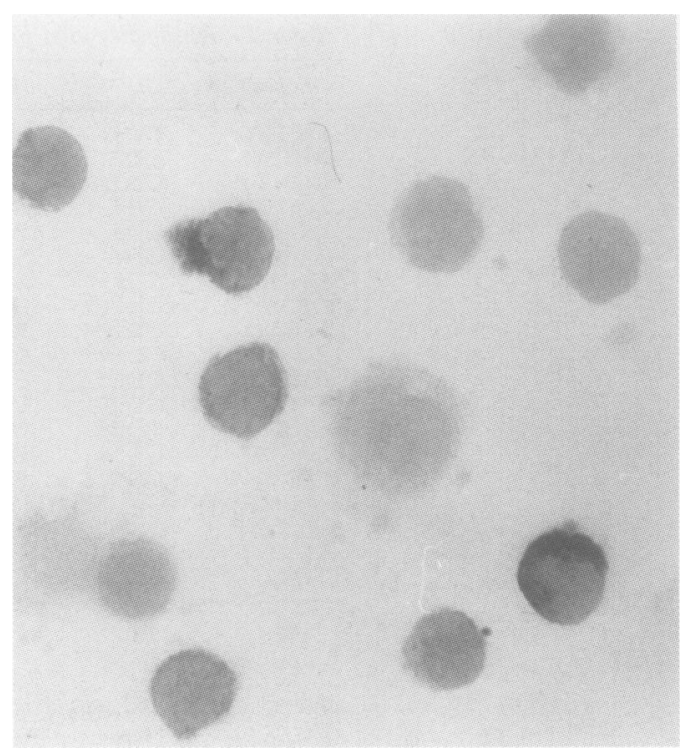

Figure 3 Lymphocytes from a case of LGL leukaemia, some of which are positive with TIA-2 (APAAP).

leukaemia than in PTCL, T-ALL, and T lymphocytosis (figs 1 and 2). TIA-1 was negative in Sezary syndrome and T-PLL except for one T-PLL weakly positive in $34 \%$ of cells.

TIA- 2 was positive in $60 \%$ of cases, with no differences according to disease type except for PTCL, where this marker was rarely positive (figs 3 and 4) (table 3).

CORRELATION BETWEEN EXPRESSION OF TIA- 1 AND TIA-2 AND A CD4 + AND/OR CD8 + PHENOTYPE AND OTHER T CELL AND NK MARKERS

Table 4 shows the correlation between the expression of TIA-1 and a CD8 + or CD4+ phenotype. Although it would appear that TIA1 was more frequently positive in cases with $\mathrm{CD} 8+, \mathrm{CD} 4-$ and CD8-, CD4 - phenotypes, this was because most cases with these markers corresponded to LGL leukaemia. When considering each disease category, particularly LGL leukaemia, TIA-1 was positive regardless of the marker profile, albeit slightly more often in cases where cells were CD8+. There was no correlation between TIA-2 expression according to the reactivity with CD4 and CD8, nor with that of other $T$ cell markers, particularly membrane CD3 and $T$ cell activation markers (data not shown).

Table 5 shows the correlation between the reactivity with TIA-1 and TIA-2 and the expression of NK markers in LGL leukaemia.

Table 4 Correlation between TIA-1 expression and a CD4 and/or CD8 positive phenotype (number and proportion of TIA-1 positive cases)

\begin{tabular}{lllll}
\hline Disease & $C D 4+, C D 8-$ & $C D 4-, C D 8+$ & $C D 4+, C D 8+$ & $C D 4-, C D 8-$ \\
\hline LGL leukaemia & $2 / 3(66 \%)$ & $17 / 21(81 \%)$ & $1 / 1(100 \%)$ & $4 / 6(67 \%)$ \\
T-PLL & $0 / 2(0 \%)$ & $0 / 3(0 \%)$ & $1 / 4(25 \%)$ & \\
Sezary syndrome & $0 / 4(0 \%)$ & $1 / 1(100 \%)$ & $0 / 1(0 \%)$ & $1 / 1(100 \%)$ \\
PTCL & $0 / 2(0 \%)$ & $0 / 2(0 \%)$ & & $1 / 1(100 \%)$ \\
T-ALL & $0 / 6(0 \%)$ & $2 / 3(67 \%)$ & & \\
T cell lymphocytosis & $2 / 17(12 \%)$ & $20 / 30(67 \%)$ & $2 / 6(33 \%)$ & $6 / 8(75 \%)$ \\
Total &
\end{tabular}

LGL leukaemia = large granular lymphocyte leukaemia; T-PLL=T-prolymphocytic leukaemia; PTCL=peripheral T-cell lymphoma; $\mathrm{T}-\mathrm{ALL}=\mathrm{T}$-acute lymphoblastic leukaemia. 


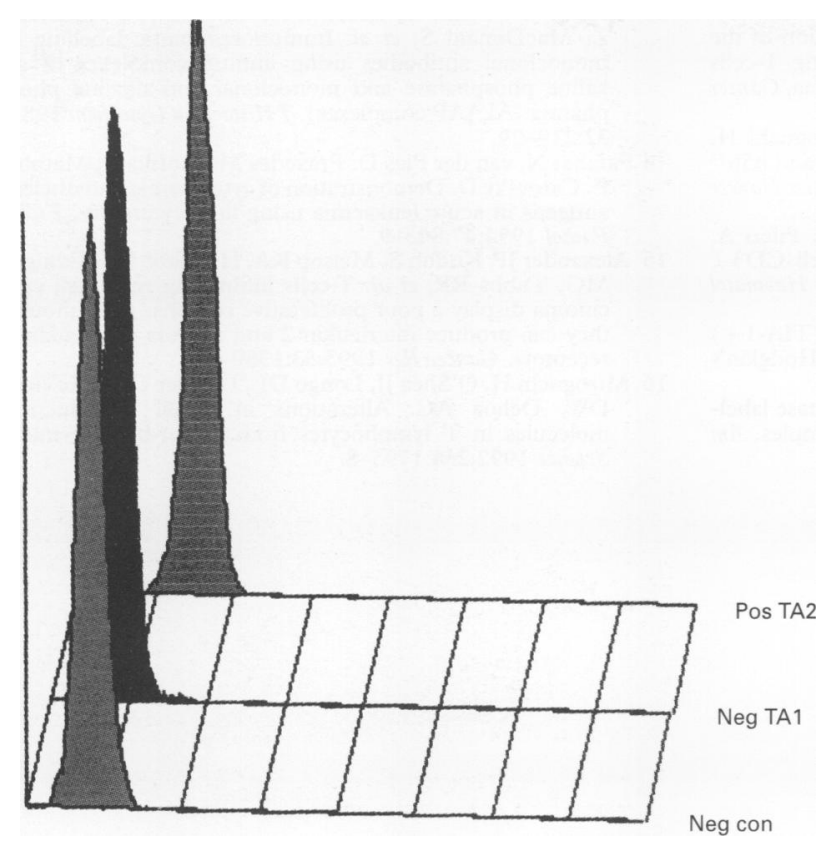

Figure 4 FACS profile of a case of T-PLL positive with TIA-2 and negative with TIA-1.

Table 5 Correlation between TIA-1 and TLA-2 expression and NK markers in LGL leukaemia (number and proportion of cases positive with $T I A-1$ and $T L A-2$ )

\begin{tabular}{lcl}
\hline NK marker & $T L A-1$ & $T L A-2$ \\
\hline CD11b+ & $13 / 17(76 \%)$ & $11 / 14(78 \%)$ \\
CD11b- & $9 / 10(90 \%)$ & $12 / 15(80 \%)$ \\
CD16+ & $8 / 8(100 \%)$ & $4 / 6(67 \%)$ \\
CD16- & $10 / 14(71 \%)$ & $5 / 6(83 \%)$ \\
CD56+ & $7 / 8(87 \%)$ & $5 / 6(83 \%)$ \\
CD56- & $10 / 14(71 \%)$ & $7 / 10(70 \%)$ \\
CD57+ & $11 / 13(85 \%)$ & $9 / 12(75 \%)$ \\
CD57- & $5 / 7(71 \%)$ & $2 / 3(67 \%)$ \\
\hline
\end{tabular}

TIA-1 was more often positive in cases where cells were positive with CD16, CD56, and CD57. In contrast, there were no differences on TIA-2 expression with respect to any of the NK markers.

\section{Discussion}

The T-lymphoproliferative disorders are heterogeneous in their clinical and laboratory features. This is also reflected on the immunological markers as there is no evidence of phenotypes unique to a particular disease except LGL leukaemia. ${ }^{2}$

We have shown here that TIA-1 is expressed in cells from the majority of cases of LGL leukaemia and, as a rule, is negative in the other $\mathrm{T}$ cell diseases. Although cells from some PTCL and T-ALL were TIA-1 positive, the number of cases was too small to draw conclusions. Cases with reactive $T$ cell lymphocytosis which could be confused with LGL leukaemia were less often TIA-1 positive. The fact that TIA-1 expression did not correlate with the cells being CD8 + or CD4+ but rather with granular lymphocyte morphology suggests that it might possibly be of value in the differential diagnosis between LGL leukaemia with Sezary syndrome and T-PLL, as cells from several T-PLL and Sezary syndrome cases had a CD8 +, CD4 - or a CD8 +, CD4 + phenotype, the former phenotype being common in LGL leukaemia.

Our results suggest that most cases of LGL leukaemia arise from the expansion of CD8+, TIA-1 + lymphocytes with a possible cytotoxic function. Six cases (four LGL leukaemia, one PTCL, and one T-ALL) who had a CD4-, CD8 - phenotype stained with TIA- 1 but none had a pure NK phenotype profile and all but one were $\mathrm{CD} 3+$; the $\mathrm{CD} 3$ negative case was positive with other $T$ cell markers. Probably none of them represented a proliferation of TIA-1 positive NK cells.

The pattern of staining with TIA-2 was more variable, without evidence of an association with a particular disease. A proportion of cases were TIA-2 negative and thus lacked the TCR$\zeta$ chain which plays a key role as a signal transducing molecule during activation of $\mathrm{T}$ and NK cells. This suggests indirectly an impaired immunological function for such leukaemic cells. Indeed, a decrease in the cytotoxic and proliferative response to signalling through the TCR has been shown in mice lymphocytes which lack the TCR- $\zeta$ chain or express it poorly. ${ }^{15}$ The lack of TCR- $\zeta$ in leukaemic T cells was unrelated to the expression of CD3 or CD16, molecules to which the TCR- $\zeta$ chain is associated in T and NK cells, respectively. The lack of or weak expression of TIA-2 is also found in tumour infiltrating lymphocytes in mice and humans ${ }^{8916}$ and it has recently been reported in non-neoplastic $T$ cells in a case of $\mathrm{B}$ cell non-Hodgkin's lymphoma. ${ }^{10}$ Its absence in some $\mathrm{T}$ cell malignancies might be useful in monitoring response to treatment.

In conclusion, we report the spectrum of reactivity of two new monoclonal antibodies, TIA-1 and TIA-2, in a variety of T cell disorders. We have shown that TIA-1 is a useful marker for LGL leukaemia and that TIA-2 might be helpful in monitoring the disease status in patients whose cells are negative for this monoclonal antibody.

The monoclonal antibodies TIA-1 and TIA-2 were provided by Coulter Clone. We are grateful to Prof $G$ Janossy, Prof $P$ Beverley, and Prof F Garrido for the gift of some of the antibodies used in this study.

1 Bennett JM, Catovsky D, Daniel MT, Flandrin G, Galton DAG, Gralnick HR, et al. The French-American-British (FAB) Cooperative Group. Proposals for the classification of chronic $B$ and $T$ lymphoid leukaemias. $\mathcal{F}$ Clin Pathol 1989;42:567-84.

2 Matutes E, Catovsky D. Mature T-cell leukemias and leukemia/lymphoma syndromes. Review of our experience in 175 cases. Leukemia Lymphoma 1991;4:81-91.

3 Anderson P, Nagler-Anderson C, O'Brien C, Levine $H$, Waatkins S, Slayter HS, et al. A monoclonal antibody reactive with a $15 \mathrm{kDa}$ cytoplasmic granule associated protein defines a subpopulation of CD8 + T-lymphocytes. protein defines a subpopulation

4 Anderson P, Blue ML, O'Brien C, Schlossman SF. Monoclonal antibodies reactive with the $T$ cell receptor $\zeta$ chain: production and characterization using a new method. $f$ Immunol 1989;143:1899-904

5 Anderson P, Caliguri M, Ritz J, Schlossman SF. CD3negative natural killer cells express $\zeta$ TCR as part of a novel molecular complex. Nature 1989;341:159-62

6 Anderson P, Caligiuri M, RikJ, Schlossman SF. Fc $\gamma$ receptor type III (CD16) is included in the $\zeta$ NK receptor complex expressed by human natural killer cells. Proc Natl Acad Sci USA 1990;87:2274.

7 Vivier E, Rochet N, Kochan JP, Presky DH, Schlossman $\mathrm{SF}$, Anderson P. Structural similarity between Fc receptors and $T$ cell receptors. Expression of the $\gamma$-subunit of FC $\varepsilon$ in human $T$ cells, natural killer cells and thymocytes. $\mathcal{F}$
Immunol 1991;147:4263-70. 
8 Nakagomi H, Peterssonn M, Magnusson I, Juhlia C, Matsuda $M$, Mellstedt $H$, et al. Decreased expression of the signal-transducing $\zeta$ chains in tumor-infiltrating T-cells and NK cells of patients with colorectal carcinoma. Cancer Res 1993;53:5610-2.

9 Finke JH, Zea AH, Stanley J, Longo DL, Mizoguchi $H$, Tubbs RR, et al. Loss of T-cell receptor $\zeta$ chain and $\mathrm{p} 56^{\text {lck }}$ in T-cells infiltrating

10 Massaia M, Attisano C, Beggiato E, Bianchi A, Pileri A Correlation between disease activity and $\mathrm{T}$ cell $\mathrm{CD} 3 \zeta$ Correlation between disease activity and $\mathrm{T}$ cell $\mathrm{CD} 3 \zeta$
chain expression in a B-cell lymphoma. $\mathrm{Br} f \mathrm{Haematol}$ chain expression

11 Diaz J, Tubbs R, Stoler M, Grogan T. Cytolytic (TIA-1 +) tumor infiltrating lymphocytes in B cell non-Hodgkin's lymphomas. Leukemia Lymphoma 1993;9:91-4.

12 Erber WN, Mason DY. Immunoalkaline phosphatase labelling of terminal transferase in hematological samples. $\mathrm{Am}$ $f$ Clin Pathol 1987;88:43-50.
13 Cordell JL, Falini B, Erber WN, Ghosh WN, Abdulaziz $\mathrm{Z}$, MacDonald S, et al. Immunoenzymatic labelling of monoclonal antibodies using immunocomplexes of alkaline phosphatase and monoclonal anti-alkaline phosphatase (APAAP complexes). $\mathcal{F}$ Histochem Cytochem 1984; 32:219-29.

14 Farahat N, van der Plas D, Praxedes M, Morilla R, Matutes E, Catovsky D. Demonstration of cytoplasmic and nuclear antigens in acute leukaemia using flow cytometry. $7 \mathrm{Clin}$ Pathol 1994;47:843-9.

15 Alexander IP, Kudoh S, Melsop KA, Hamilton TA, Edinger $M G$ Tubbs $R R$ et al. T cells infiltrating renal cell carMG, Tubbs RR, et al. T-cells infiltrating renal cell carcinoma display a poor proliferative response even though they can produce interleukin 2 and express interleukin 2 receptors. Cancer Res 1993;53:1380-7.

16 Mizoguchi H, O'Shea JJ, Longo DL, Loeffler CM, McVicar DW, Ochoa AC. Alterations in signal transduction molecules in $\mathrm{T}$ lymphocytes from tumor-bearing mice. Science 1992;258:1795-8. 